\title{
The Effect of Patients Positioning on Oxygen Saturation in the Acute Phase of Ischemic Stroke
}

\author{
Mogedda Mohamed Mehany*, Magda Ahmed Mohamed**, Amal Mohamed Ahmed ${ }^{* *}$, \\ Mohamed Abdel Rahman Ahmed***
}

\begin{abstract}
Body position is known to influence respiratory function in normal subjects \& those with respiratory pathology. Its effect on respiratory function after stroke has received little attention. It's generally thought that stroke morbidity is increased by inappropriate position during early recovery phase. The present study was designed to identify changes in arterial oxygen saturation $\left(\mathrm{SaO}_{2}\right)$ associated with different four positions of the patient in order to detect proper position which maintain the optimum level of $\mathrm{SaO}_{2}$. Quasiexperiment research design was applied in this study. This study was conducted in stroke intensive care unit of Neurological Department of Assuit University Hospitals. The subjects of this study consist of 60 patients with acute ischemic stroke within 48 hours following mild to moderate and sever stroke. Three tools were included in the study, tool of sociodemographic data, tool of the positions and tool of the Scandinavian stroke scale. The result of the present study revealed that there was statistically significant difference between $\mathrm{SaO}_{2}$ and blood pressure of the patients before and after the positions. It was found also that total mean of $\mathrm{SaO}_{2}$ during right side, supine and semi-setting position was nearly equal and there was statistically significant difference between left position and 3 other positions. So, the study recommended the importance of changing patient's positions which improve ventilation and blood pressure. The importance of the use of positions tested (Rt. side, supine and semi-setting position) in the clinical practice to maintain $\mathrm{SaO}_{2}$ in patients of ischemic stroke.
\end{abstract}

\section{INTRODUCTION}

Stroke is the third leading cause of stroke related disorders. ${ }^{(2)}$ Stroke is a death \& adult disability preceded by heart descriptive term for the onset of acute disease \& cancer. ${ }^{(1)}$ According to the neurological deficit persisting for more than National Stroke Association stroke is one 24 hours \& caused by the interruption of of the leading causes of permanently blood flow to the brain. Strokes are disability in adult. American Heart generally classified as either ischemic Association estimated that 15 to 20 billion or hemorrhagic, while approximately dollars are spent annually on stroke \& $80 \%$ of all strokes are ischemic. Ischemic

\footnotetext{
${ }^{*}$ Critical Care Nursing, Faculty of Nursing, Assuit University

${ }^{* *}$ Medical-Surgical Nursing, Faculty of Nursing, Assuit University

${ }^{* \star *}$ Neurological department Faculty of Medicine, Assuit University
} 
strokes result from low cerebral blood flow usually because of occlusion of blood vessels. The occlusion can be either thrombi or emboli. ${ }^{(1-4)}$ Early recognition \& prompt entry into emergency medical system are essential to reduce death \& disability from stroke.(2,5) It's generally agreed that hypoxia should be avoided in the acute phase of stroke. Full in oxygenation could affect the vulnerable ischemic brain. ${ }^{(6)}$ Body position is known to influence respiratory function in normal subjects \& those with respiratory pathology. Its effect on respiratory function after stroke has received little attention. ${ }^{(6)}$ It's generally thought that stroke morbidity is increased by inappropraite positioning during early recovery phase. ${ }^{(7,8)}$ Until now, for patients with ischemic stroke no studies to date have evaluated the effect of patients positioning on stroke out come..$^{(9,10)}$ Although there are no data from standardized studies, moderate elevation of the head is standard practice in most institutions. ${ }^{(10)}$ However, one study suggests the some positions used in clinical practice may adversely influence respiratory function. That Study aimed at identifying effect of these positions to maintain arterial oxygen saturation $\left(\mathrm{SaO}_{2}\right)$ at optimal level and changes in $\mathrm{SaO}_{2}$ during time spent in the test positions. The study reported that there were no changes in $\mathrm{SaO}_{2}$ across the hour spent in each position and no differences in $\mathrm{SaO}_{2}$ were identified among positions. ${ }^{(5)}$ It's clear from the researches that few which were directed specifically toward positioning, the patient with ischemic stroke which reflects the need for further research to supplement the present body knowledge. Hence this study was designed to identify changes in $\mathrm{SaO}_{2}$ associated with different position of the patients in order to detect proper positioning which maintains the optimum level of $\mathrm{SaO}_{2}$.

\section{AIM OF THE STURY}

1- To identify changes in arterial 
Oxygen saturation $\left(\mathrm{SaO}_{2}\right)$ associated with different positions of the patients

2- To detect proper position which maintains the optimum level of $\mathrm{SaO}_{2}$.

\section{MATERIAL and METHODS}

Design: Quasiexperimental research design was adopted for this study. Setting: The study was carried out in the stroke intensive care unit of Neurological Department of Assuit University Hospital.

Subjects: Convenient sample of 60 patients were included in this study. The subjects were eligible for the study if they had first anterior circulation acute ischemic stroke within 48 hours following mild to moderately \& sever stroke.

\section{Exclusion criteria:}

1- Patients with hemorrhagic stroke

2- Patients with organ failure (hepatic, renal \& cardiac disease)

3- Uncooperative patients

4- Patients with severe chest infection

5- Patients with recent myocardial infarction
Tools: three tools were developed for data collection: Tool of socio-demographic data (age, sex, marital status \& level of education)

Tool of positions : in this tool blood pressure \& $\mathrm{SaO}_{2}$ were recorded before \& after positions, $\mathrm{SaO}_{2}$ was recorded in this tool each 15 minutes during hour spent in semi-setting, supine, right side \& left side position.

Tool of the scale: Scandinavian stroke scale tool(11) to assess neurological status of patient with ischemic stroke with total score of (58).

\section{This scale composed of 9 items:}

The first one for assessment of level of consciousness with score $(6-4-2)$. The $2^{\text {nd }}$ item for assessment of orientation with score $(6-4-2-0)$. The $3^{\text {rd }}$ item related to assessment of eye movement with score (4-2-0). The $4^{\text {th }}$ item for assessment of facial palsy with score $(2-0)$. The $5^{\text {th }}$ item for assessment of arm motor power with score $\quad(6-5-4-2-0)$. The $6^{\text {th }}$ item for 
assessment of hand motor power with score $(6-4-2-0)$. The $7^{\text {th }}$ item for assessment of leg-motor power with score of $(6-5-4-2-0)$. The $8^{\text {th }}$ item for assessment of gait with score $(12-9-6-3-0)$. The last $9^{\text {th }}$ item for assessment of speech with score $(10-6-3-0)$.

\section{Methods}

- Permission to conduct the study was taken from hospital responsible authorities after explanation of the aim of the study.

- Data collection tools were developed based on review of relevant literature.

- The study tools were revised by 5 experts in the field of nursing \& neurology to test content validity \& clarity. Necessary modifications were done.

- A pilot study was conducted on 5 patients not included in the study to test feasibility of the tool.

- All patients included in the study were informed about the aim of the study \& all of them gave informed consent before engaging in the study if possible.

In this study, each patient was put in four positions (semi-setting, supine, right side \& left side position)

- Before putting the patient in any position, blood pressure \& $\mathrm{SaO}_{2}$ were measured and recorded in tool number (2).

- The patients still in each position for one hour, during this hour $\mathrm{SaO}_{2}$ was measured \& recorded every 15 minutes in that hour.

After finishing from the four positions the blood pressure \& $\mathrm{SaO}_{2}$ were measured \& recorded also in tool number (2).

- After that neurological status of each patient. was assessed by using Scandinavian scale through observation \& interview of the patient if possible.

\section{Statistical analysis}


Data were analyzed using SPSS, to means of blood pressure \& $\mathrm{SaO}_{2}$. The version 11-5. A $p$ value of 0.05 was used Table and Figure indicate that the mean for statistical significance and all tests were of the blood pressure and $\mathrm{SaO}_{2}$ of the two sided. The arithmetic mean, standard deviation \& percentage were used as $(142 \pm 23.412, \quad 86.5 \pm 11.472 \& 94.36 \pm 3.0$ summary statistics. Comparison among proportion was performed using T-test, 89, respectively) which improve to $(131.67 \pm 20.380, \quad 81.667 \pm 17.434 \quad$ \& correlation \& regression with exact $p$ 95.6 \pm 2.216$)$ after finishing from study values.

\section{RESULTS}

positions. This table showed also that there were statistically significant difference

A total of 60 patients were enrolled in this study:

between means of the blood pressure and $\mathrm{SaO}_{2}$ of the patients before \& after

Table (1) \& figure (1) show the sociodemographic characteristics of the study sample, The mean age of the patients was (54.416) years, while more than half of the patients (58\%) were males \& $(42 \%)$ were females. It was apparent from this table also that majority $(86.67 \%)$ of the patients were married \& the highest proportion $(75 \%)$ of the patients were illiterate or just know how to read \& write.

Table (2) \& figure (2) illustrated the distribution of the studied sample according positions.

Table (3) \& figure (3) review the distributation of the studied sample according to mean of $\mathrm{SaO}_{2}$ during hour spending in each position. It was found that mean of $\mathrm{SaO}_{2}$ in the last 15 minutes of the hours was the highest mean in the majority of the positions. It was clear from the table also that total mean of $\mathrm{SaO}_{2}$ during hour spending in each position in the right side, supine \& semi sitting position was nearly equal. 
Table (4): shows the significant were $(3.3 \pm 1.7,2.6 \pm 1.7,2.2 \pm 1.7,2 \pm 3.2$, difference between positions. It was found and $3.3 \pm 2.9$, respectively).

that there were statistical significant

It was clear from the table also that differences between left position \& the mean score of the all items of the scale three other positions (right side, supine \& was very poor in comparison to total score. semi-sitting position)

Table (6): shows correlation between

Table (5): illustrated distribution of the study sample according to mean score of Scandinavian stroke scale.

The table reviews that the mean scores of level of consciousness, orientation, eye movement \& facial palsy of the studied sample were $(3.11 \pm 1.438,2.433 \pm 1.807$, positions \& Scandinavian stroke scale. It was found that there were statistical significant differences between left side, and supine position \& level of consciousness \& between left side position $\&$ hand motor power.

It was noticed also that there were $2.1 \pm 1.537$, and $1.1 \pm 1.003$, respectively). statistically significant differences between While in arm, hand, leg motor power, gait \& the right side position and supine position speech, mean scores of the studied group \& gait item.

Table (1) Distribution of the studied sample according to their socio-demographic characteristics, number $=60$ patients

\begin{tabular}{|l|c|c|c|}
\hline \multicolumn{1}{|c|}{ Variables } & Frequency & $\%$ & Mean +SD \\
\hline Age & - & - & $54.416+10.722$ \\
\hline Sex & 35 & 58 & \\
Male & 25 & 42 & \\
Female & 52 & 86.67 & \\
Marital status & 8 & 13.33 & \\
Married & & & \\
Unmarried & 39 & 65 & \\
\hline Level of education & 6 & 10 & \\
Illiterate & 11 & 18 & \\
Read \& write & 4 & 7 & \\
Primary/prep school & & \\
Secondary school & &
\end{tabular}



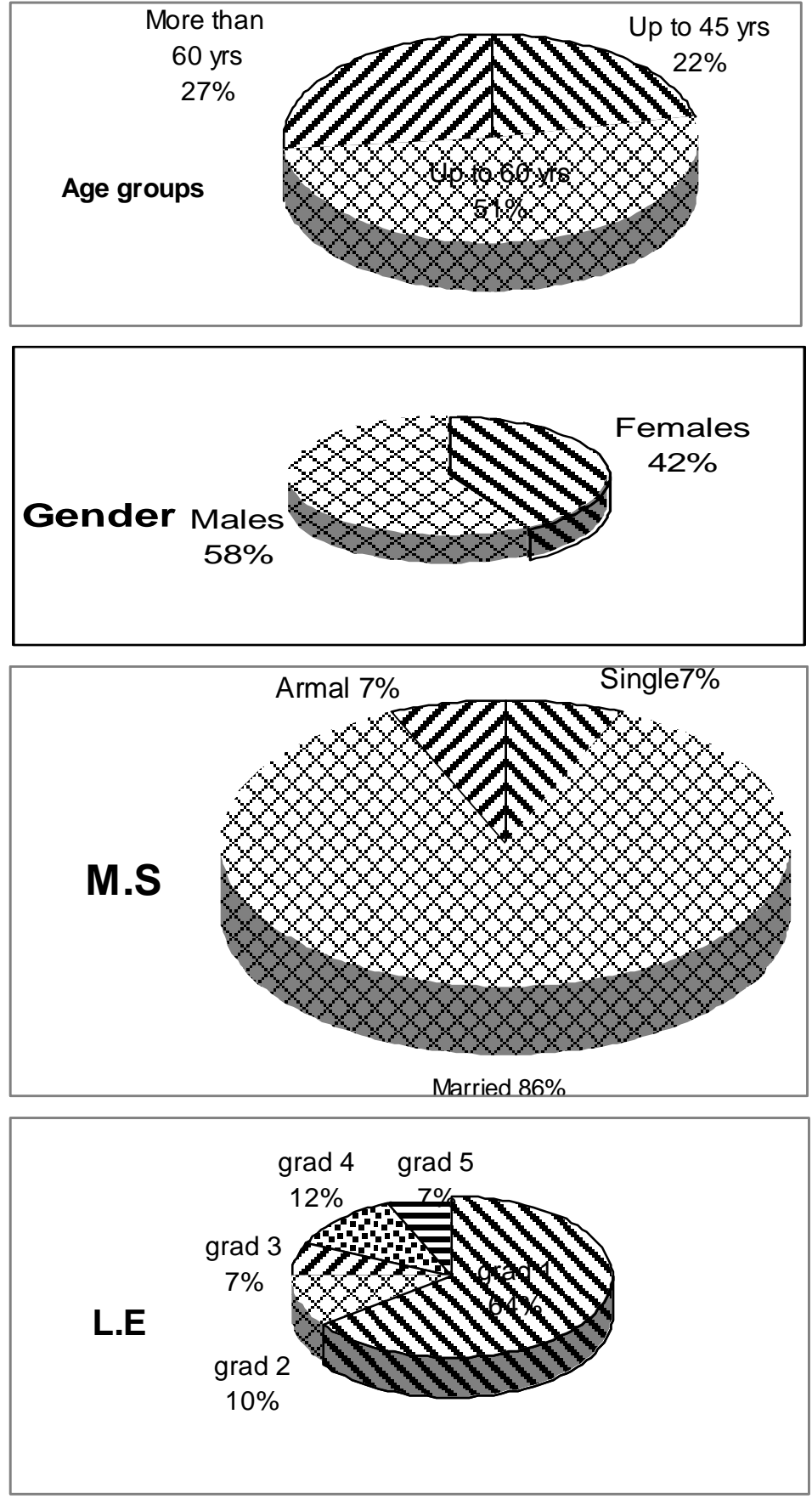

Figure (1) Distribution of the studied sample according to their sociodemographic characteristics. 
Table (2): Distribution of the studied sample according to blood pressure \& $\mathrm{SaO} 2$ before \& after positions

\begin{tabular}{|c|c|c|c|}
\hline \multicolumn{1}{|c|}{ Variable } & $\begin{array}{c}\text { Before positions } \\
\text { Mean +SD }\end{array}$ & $\begin{array}{c}\text { After positions } \\
\text { Mean +SD }\end{array}$ & Significance \\
\hline $\begin{array}{c}\text { Blood pressure } \\
\text { a- Systolic }\end{array}$ & $142+23.412$ & $131.67+20.80$ & $\begin{array}{c}\text { T value } \\
3.96 \\
\text { b- Diastolic } 0.002 \\
\text { T value }\end{array}$ \\
** \\
SaO2 & $86.5+11.472$ & $81.667+17.434$ & $\begin{array}{c}\text { T value } \\
\text { ** } \\
4.65\end{array}$ \\
\hline
\end{tabular}

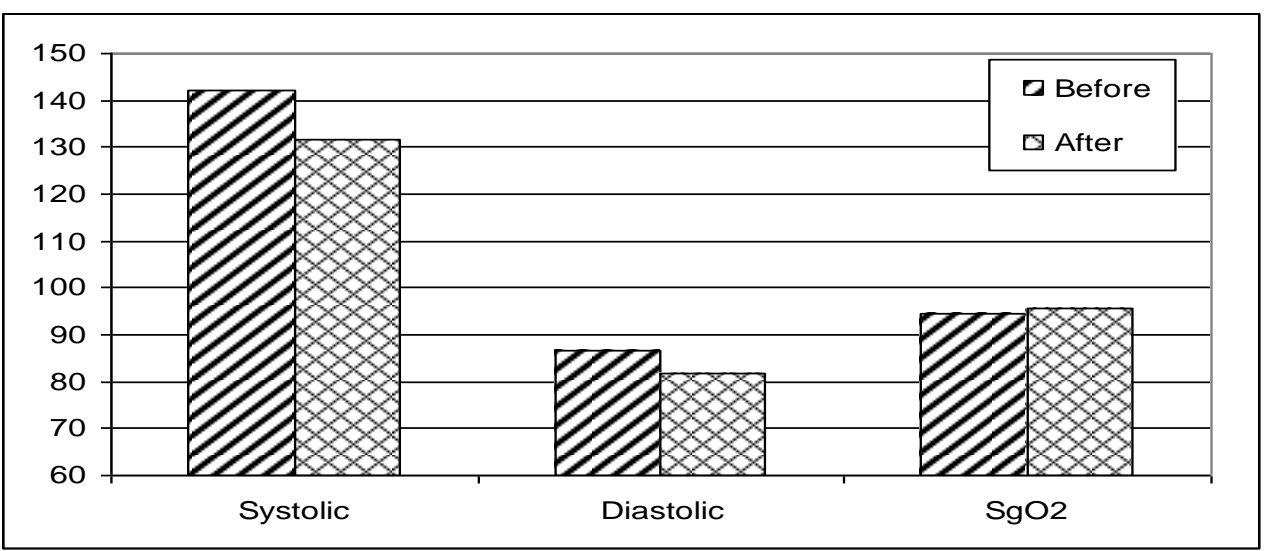

Figure (2) distribution of the studied sample according to blood pressure \& $\mathrm{SaO}_{2}$ before \& after positions

Table (3) Distribution of the studied sample according to mean of $\mathrm{SaO}_{2}$ during hour spending in each position.

\begin{tabular}{|l|c|c|c|c|c|}
\hline \multicolumn{1}{|c|}{ Positions } & $\begin{array}{c}1^{\text {st } 15} \text { minutes } \\
\text { of the hour }\end{array}$ & $\begin{array}{c}2^{\text {nd }} 15 \text { minutes } \\
\text { of the hour }\end{array}$ & $\begin{array}{c}3^{\text {rd }} 15 \text { minutes } \\
\text { of the hour }\end{array}$ & $\begin{array}{c}4 \text { th } 15 \text { minutes } \\
\text { of the hour }\end{array}$ & Total hours \\
\hline Rt. side & $94.633 \pm 2.767$ & $94.4 \pm 2.775$ & $94.733 \pm 2.510$ & $94.95 \pm 2.324$ & $94.688 \pm 2.449$ \\
\hline Supine & $94.833 \pm 3.03$ & $94.8 \pm 2.113$ & $94.786 \pm 2.082$ & $94.9 \pm 2.242$ & $94.683 \pm 2.066$ \\
\hline $\begin{array}{l}\text { Semi- } \\
\text { setting }\end{array}$ & $94.2 \pm 2.660$ & $94.366 \pm 2.916$ & $94.466 \pm 2.632$ & $94.05 \pm 2.324$ & $94.296 \pm 2.454$ \\
\hline Left side & $93.833 \pm 2.756$ & $93.25 \pm 3.457$ & $93.25 \pm 3.457$ & $93.466 \pm 3.088$ & $93.479 \pm 2.874$ \\
\hline
\end{tabular}




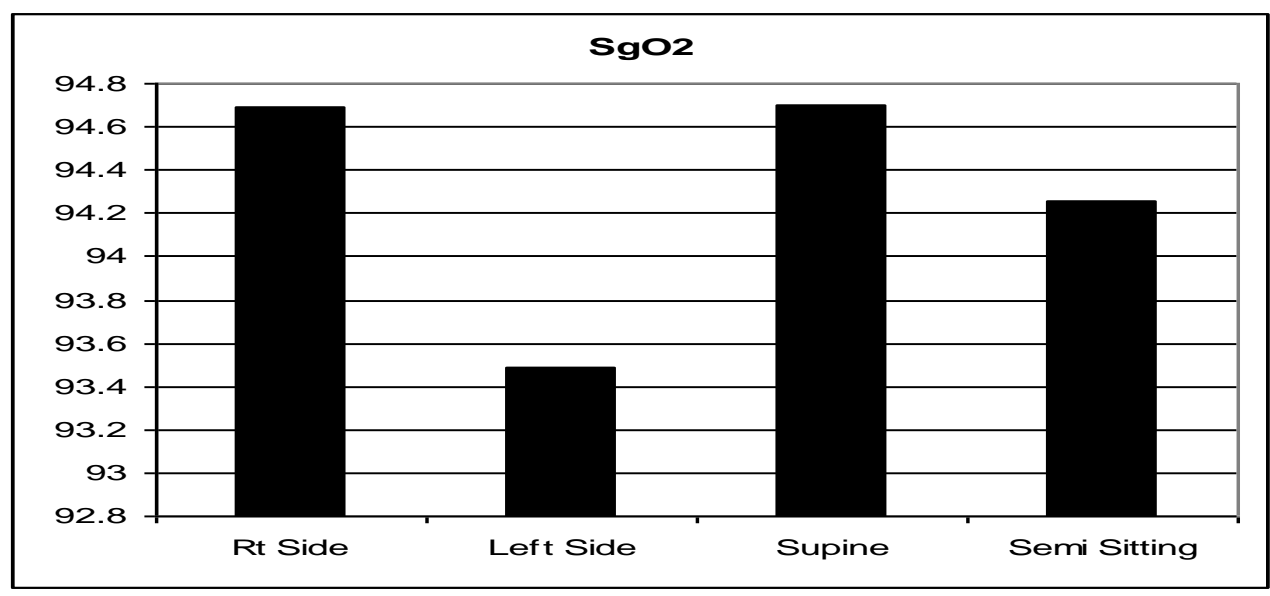

Figure(3) Distribution of the studied sample according to mean of $\mathrm{SaO}_{2}$ during hour spending in each position

Table (4) Significance differences in $\mathrm{SaO}_{2}$ between positions

\begin{tabular}{|l|c|c|c|}
\hline \multicolumn{1}{|c|}{ Positions } & Rt side (94.69) & Left side (93.48) & Supine (94.68) \\
\hline $\begin{array}{l}\text { Left side } \\
\text { (93.48) }\end{array}$ & T value, $\mathrm{p}$ & & \\
\hline Supine & $3.55 \quad 0.0008^{* *}$ & & \\
(94.68) & 0.69 & 3.57 & \\
\hline Semi-sitting & $0.493 \mathrm{~ns}$ & $0.0007^{\star *}$ & 1.02 \\
(94.29) & $0.085 \mathrm{~ns}$ & $0.028^{*}$ & $0.31 \mathrm{~ns}$ \\
\hline
\end{tabular}

$$
\begin{aligned}
& \text { Ns = non-significant } \\
& { }^{*}=\text { significant } \\
& { }^{* *}=\text { highly significant }
\end{aligned}
$$

Table (5) Distribution of the study sample according to score of Scandinavian stroke scale.

\begin{tabular}{|l|c|}
\hline \multicolumn{1}{|c|}{ Items of scale } & Mean +SD \\
\hline Consciousness (6-4-2) & $3.114 \pm 1.438$ \\
\hline Orientation (6-4-2-0) & $2.433 \pm 1.807$ \\
\hline Eye movements (4-2-0) & $2.1 \pm 1.537$ \\
\hline Facial palsy (2-0) & $1.1 \pm 1.003$ \\
\hline Arm, motor power (6-5-4-2-0) & $3.383 \pm 1.747$ \\
\hline Hand motor power (6-4-2-0) & $2.683 \pm 1.747$ \\
\hline Leg motor power (6-5-4-2-0) & $2.233 \pm 1.681$ \\
\hline Gait (12-9-6-3-0) & $2.0 \pm 3.204$ \\
\hline Speech (10-6-3-0) & $3.283 \pm 2.888$ \\
\hline Total score -58 & $22.183 \pm 12.09$ \\
\hline
\end{tabular}


Table (6) Correlation between positions \& Scandinavian stroke scale .

\begin{tabular}{|c|c|c|c|c|c|c|c|c|c|}
\hline \multirow[b]{2}{*}{ 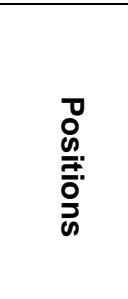 } & \multicolumn{9}{|c|}{ Items of the scale } \\
\hline & 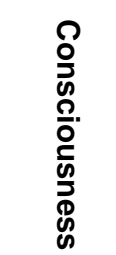 & 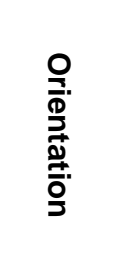 & 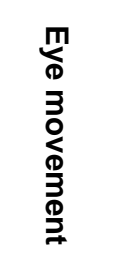 & 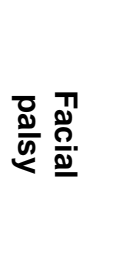 & 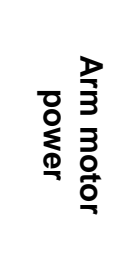 & 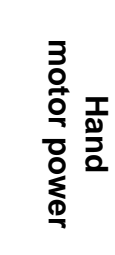 & 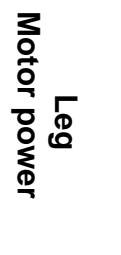 & $\stackrel{\circ}{\stackrel{\varrho}{\rightleftharpoons}}$ & $\begin{array}{l}0 \\
\stackrel{0}{8} \\
\mathbb{D} \\
\stackrel{\$}{Y}\end{array}$ \\
\hline Rt. side & $0.15 \mathrm{~ns}$ & $0.07 \mathrm{~ns}$ & $0.12 \mathrm{~ns}$ & $0.08 \mathrm{~ns}$ & $0.33 \mathrm{~ns}$ & $0.64 \mathrm{~ns}$ & 0.31 * & $0.09^{* *}$ & $0.45 \mathrm{~ns}$ \\
\hline Left side & $0.28^{*}$ & $0.10 \mathrm{~ns}$ & $0.20 \mathrm{~ns}$ & $0.49 \mathrm{~ns}$ & $0.44 \mathrm{~ns}$ & $0.67^{\star *}$ & $0.14 \mathrm{~ns}$ & $0.33 \mathrm{~ns}$ & $0.62 \mathrm{~ns}$ \\
\hline $\begin{array}{l}\text { Semi- } \\
\text { setting }\end{array}$ & $0.12 \mathrm{~ns}$ & $0.56 \mathrm{~ns}$ & $0.69 \mathrm{~ns}$ & $0.72 \mathrm{~ns}$ & $0.42 \mathrm{~ns}$ & $0.47 \mathrm{~ns}$ & $0.27 \mathrm{~ns}$ & $0.33 \mathrm{~ns}$ & $0.33 \mathrm{~ns}$ \\
\hline
\end{tabular}

\begin{tabular}{rl|c|c|c|c|c|c|c|c|c|}
\hline Supine & $0.27^{*}$ & $0.16 \mathrm{~ns}$ & $0.41 \mathrm{~ns}$ & $0.64 \mathrm{~ns}$ & $0.70 \mathrm{~ns}$ & $0.75 \mathrm{~ns}$ & $0.27 \mathrm{~ns}$ & $0.05^{*}$ & $0.53 \mathrm{~ns}$ \\
\hline & *s = not significant \\
$*$ Significant at $1 \%$ & * Significant at $5 \%$ \\
\hline
\end{tabular}

\section{DISCUSSION}

Body position is known to influnance respiratory function in normal subjects \& those with respiratory pathologists. Its effect on respiratory function after stroke has received little attention. ${ }^{(6)}$ It is generally thought that stroke morbidity is increased by inappropriate position during early recovery phase ${ }^{(7,8)}$. So the present study tried to identify changes in $\mathrm{SaO}_{2}$ associated with different four positions of the patient in order to detect proper position which maintains the optimum level of $\mathrm{SaO}_{2}$. The present study study done by stroke information of the revealed that mean age of the patient was $54.416 \pm 10.722$, while more than half of the patients were males. This result may be attributed to that males were more smoker, more stressfull \& have more high cholesterol than females. The results of the present study were in line with study done by Schwarz, et al., (10) on the effect of body position on cerebral perfusion in patients with stroke, who stated that mean age of the patients was 61.2 years while more than half of the patients were males. Also 
patient family ${ }^{(12)}$ who mentioned that $28 \%$ of people suffer stroke in given year are under age of 65 years. While Hicks ${ }^{(13)}$ who stated that stroke can affect people of any age. Nine out of ten stroke occur in people over the age of 55 years. Hicks mentions also that men are more often affected by stroke than women. The present study demonstrated that the highest proportions of the patients were illiterate or can read \& write. This level of education may be a barrier to complaine with treatment and awareness of the warning signs of the stroke.

So a primary public health should focus on increased the awareness of the stroke symptoms particularly among people at high-risk to decrease delay in early detection \& effective stroke treatment.

The current study revealed that blood pressure $\& \mathrm{SaO}_{2}$ of the studied sample after finishing from position were better than blood pressure $\& \mathrm{SaO}_{2}$ before starting positions. There were statistical significant differences between blood pressure \& $\mathrm{SaO}_{2}$ before \& after positions. This result may be attributed to change of body positions can improve circulation \& ventilation.

Changing position can improve oxygenation by improved ventilation perfusion matching \& prevention of complication(14-15). Study done by Schworz, et al.,(10) on the effect of body positions on cerebral perfusion in patients with stroke, mention that baseline mean arterial pressure of the patients was $90.0 \pm 1.6$ $\mathrm{mm} / \mathrm{hg} \&$ fell to $82.7 \pm 1.7 \mathrm{mmhg}$ at 15 degrees \& $79.1 \pm 1.6 \mathrm{~mm} / \mathrm{hg}$ at 30 back rest elevation. Pugh et al.,(2004) mentioned that it's important to monitor blood pressure frequently during the acute phase of the stroke. (3)

Yeaw (1992)(16) mentioned that before any position change of the stroke patient, assess the patient to determine baseline data as respiration, blood pressure, mental status \& $\mathrm{SaO}_{2}$ to evaluate the effect of the 
position, change by comparing your findings before \& after change of position to your base line assessment.

It was clear from the results of the present study that the highest mean of $\mathrm{SaO}_{2}$ of the study subject during total hours spent in the position, was in the right side followed by supine position \& semi-setting position \& it was noticed that differences between means of $\mathrm{SaO}_{2}$ in the three mentioned positions were very little \& there was statistically significant difference between left side position \& these three mentioned positions.

While study done by chalterton, et al., $(2000)^{(6)}$ who reported that mean $\mathrm{SaO}_{2}$ values for all patients were $>90$ for the hour spent in each test position. For all patients there were no changes in $\mathrm{SaO}_{2}$ across the hour spent in the test position difference in $\mathrm{SaO}_{2}$.

Study done by Brainin ${ }^{(17)}$ who tested the safety of positioning the stroke patient on the left side versus right side. Brainin measured oxygen saturation, breathing rate, blood pressure, pulse, \& ECG on 18 patients with stroke. There were no significant differences seen in any measurement comparing the two positions. No decrease in $\mathrm{SaO}_{2}$ was found over the course of the test for either positions.

Study done by Schworz et al., $(2002)^{(10)}$ on the effect of body position on cerebral perfusion in stroke patients, revealed that cerebral perfusion was highest in the flat position $(77.0 \pm 1.8$ $\mathrm{mm} / \mathrm{hg}) \&$ decreased to $70.0 \pm 1.8 \mathrm{~mm} / \mathrm{hg}$ at 15 further to $64.7 \pm 1.7 \mathrm{~mm} / \mathrm{hg}$ at 30 perfusion return to base line value $(77.2 \pm 1.8 \mathrm{~mm} / \mathrm{hg})$ at the end of the protocol.

It was noticed from the results that scores of the studied patients as regard Scandinavian scale were very poor in comparison to total score. This may be due to the condition of the patients in early recovery phase was unstable.

The neurological scale which was used 
as standardized measure of neurological function \& stroke severity. Is a scored assessment tool that identifies neurological deficits ${ }^{(3)}$.

The patient with stroke should be assessed using the stroke scale to evaluate neurological deficits \& is useful in differentiation between ischemic stroke \& transient ischemic attack. ${ }^{(5)}$

\section{CONCLUSION}

In the light of the present study finding it might be concluded that:

1- There was statistical significant difference between blood pressure \& $\mathrm{SaO}_{2}$ before \& after study positions.

2- Total mean of $\mathrm{SaO}_{2}$ during hour spent in the right side, supine \& semi- setting position nearly equal, \& there was statistical significant difference between these positions \& left side position.

3- It was noticed also that there were statistically significant differences between the right side position, supine position and the item of (gait) of

Scandinavians stroke scale.

\section{RECOMMENDATIONS}

1- Patients with ischemic stroke in the early stage of the disease, their positions should be changed periodically to improve their condition as regard ventilation \& blood pressure.

2- The positions tested especially (Rt.side, supine \& semi-sitting position ) may be recommended for use in the clinical practice, to maintain arterial oxygen saturation in patient in the first 48 hours following mild to moderate \& sever stroke.

\section{REFERENCES}

1- Urden LD, Stacy MH, lough EM. Critical care nursing diagnosis \&management. $5^{\text {th }}$ ed. California: Mosby; 2006. 749.

2- Morton GP, fontaine D, Hudak MC.,Gallo BM. Critical care nursing. A holistic approach. $8^{\text {th }}$ ed. Philadelphia: lippincott Williams\& Wilkins; 2006. 816

3- Pugh S, Feathorstone K, Voyl MCLL, Mancini B. American Association of neuroscience nurses. 2004. Available from: www.oann.org.com.

4- Avala C, Groft JB, Greenland kJ, keenan NI, Donchoo RS, Malarcher $\mathrm{AM}$, et al. Sex differences in US 
mortality rate for stroke \& stroke race ethnicity \& age. Stroke J. 2002; 33(5):1197-2010. Available from: ciol@cdc-gov.

5- Smeltzer SC, Bare BG. Brunner \& suddarths text book of medical surgical nursing. 10th ed . ,London: Lippincott Williams \& Wilking; 2004; 1888-902.

6- Chalterton J. Connolly MJ, Clayton H. Effect of body position on arterial oxygen saturation in acute stroke, Journals of Gerontological Society of America. 2000;55, 239-44

7- George CL. .Spasticity..mechanisms and nursing Care. Journals of Nursing Clinic. North Am. 1993;28:819-27.

8- Laidler P. Rehabilitating movement, stroke rehabilitation; collaborative approach. Oxford: Block Well Science. 2000;83: 112.

9- Jones A, .Tilling K, Wilson-Barnett J, Newham DJ, Wolfe CD. Effect of recommended positioning on stroke outcome at six months; a randomized controlled trial. Clinic rehabilitation. 2005;19; 136-45.

10- Schworz S, Georgiodis D, Aschoff A, Schwob S. Effect of body position on intracranial pressure and cerebral perfusion in pts. with large hemisphere stroke, American stroke Association,2002; 33 :497-501.
Available

from:http://stroke.ahajournals.org/conte nt/full/33/2/497.

11- Nasscef B. Influence of some physiological parameters on the acute ischemic stroke out come, Master thesis. Faculty of Medicine, Assiut University: 2005 .

12- Stroke Information for Patients \& Family, Stroke Statistics, American Heart Association. 2008; 26. Available from:

http://www.strokecenter.org/patientssta ts.htm.

13- Hicks R. BBC Health condition stroke, 2008;24,456. Available from: http//wwwbbc.co.uk/health/conditions/s troke/shtml.

14- Melzler DJ, Harr J. Positioning your patient properly ,AJN march 1996;.96:3. Available from:http://www.org .ojn

15- Gowlinske A, Drocup K. Effect of positioning on $\mathrm{SVO}_{2}$ in the critically ill patient with a low ejection fraction. Nursing Research. 1998;47:5:293

16- Yeaw EM. How position affect oxygenation good lung down. AJN. 1992;92:3,28.

17- Brainin M. Stroke emergency patients should be placed on paretic side. World Congress of Neurology. 2001; 20. Available from: http.//www.ps/group .com/dg/IFEB7E. 